\title{
Global wave-driven beach evolution; consequences for observation strategies
}

\author{
Erwin W. J. Bergsma ${ }^{1, *}$, Rafael Almar $^{2}$, Thierry Garlan ${ }^{3}$, and Elodie Kestenare ${ }^{2}$ \\ ${ }^{1}$ CNES, LEGOS, UMR 5566, 14 Av. Edouard Belin, 31400, Toulouse, France. \\ ${ }^{2}$ IRD, LEGOS, UMR 5566, 14 Av. Edouard Belin, 31400, Toulouse, France. \\ ${ }^{3}$ SHOM, Dpt. of Marine Geology SHOM, Brest, France. \\ *Corresponding author: erwin.bergsma@legos.obs-mip.fr
}

\section{ABSTRACT}

It is an illusion to think that one can observe monthly beach behaviour with monthly surveys. Current coastal observation strategies restrict understanding of beach evolution, preventing effective risk mitigation. In this article, we quantify the global spatiotemporal scales of coastal wave changes, which are the known dominant driver of beach evolution. Consequences and recommendations for beach observation strategies are proposed and discussed. A global dominant time-scale of 30 days is found driving changes in average spatially correlated just over the synoptic 5 degrees regional scale $(\approx 550 \mathrm{~km}$ at the equator). Current observation-practices blind us to more than $80 \%$ of unresolved beach-change variability (shorter unresolved dynamics), leading to a large unacceptable knowledge gap. This reveals common surveying-schemes -with e.g. monthly or yearly time-interval- limit our view on the actual beach evolution, and surprisingly, even for seasonal and inter-annual evolution. The global optimal surveying time-interval -maximizing the ratio gain/effort- is found to be semi-annual, representative of the whole regional evolution. This clearly limits the use of traditional surveying strategies and promotes a paradigm shift in observational techniques towards a large-scale use (in space and time) of space-borne Earth Observation to address this challenge.

Do we know how beaches around the world evolve? Beaches are naturally dynamic as they respond to environmental conditions, such as ocean waves and sea-level changes over longer periods ${ }^{1-3}$ but also the long-term sediment balance or unbalance ${ }^{4}$. At shorter than inter-annual time-scales, it is well admitted that beach-change is predominantly driven by waves and follows wave-variability with a certain delay (memory decay). It is thus crucial to characterise their spatial and temporal scales of changes. In the mid-latitudes, storm-driven winter-waves imply a strong seasonality ${ }^{5-7}$. Similarly, in tropical regions seasonal effects are induced by monsoons and typhoons, dictating beach-change variability ${ }^{8}$. Human interventions in this natural beach behaviour often lead to an unbalanced beach system and accelerate beach erosion ${ }^{9}$. Anthropogenic pressure near the coast will increase the need for mitigating measures ${ }^{10,11}$. It is therefore paramount to understand and predict natural coastal changes to carefully mitigate immediate and long-term threats to ecosystems, human society and economic interests ${ }^{12,13}$.

Observations are key; without, one would never understand beach behaviour let alone predict $\mathrm{it}^{14}$. At a global scale, this requires the right surveying-strategy to improve the ratio gain/effort based on data. Concerning the natural variability of the beach, the timing of the survey determines the state of the beach and punctual picture one observes ${ }^{15}$. Traditionally -and remaining current practise- beach measurements are either obtained during intensive short-term field campaigns or through long-term punctual beach measurements (monthly / bi-monthly) ${ }^{16-18}$. This is always on a local scale - few $\mathrm{km}^{2}-$. Such measurements are costly, time-consuming and labour intensive. Also, these surveying schemes are predominantly found in developed mid-latitude countries, delivering a biased view and understanding. At the same time, one would agree that frequently measuring all the worlds' coastline would require an immense and unrealistic effort. Spaceborne techniques, covering large areas on a global scale, are perhaps the only feasible solutions to assess global-scale beach changes ${ }^{14}$. Nonetheless, also the 
application of these emerging techniques at the global scale is costly - in every facet; in time, computational effort and storage. Hence, optimisation in terms of surveying frequency to capture the dominant beach behaviour is therefore essential. This holds for both, traditional echo-sounding and space-borne surveys. These challenges are addressed here through three surfacing questions: 1) What are the global scales of changes of beaches under wave forcing?, 2) What are we currently measuring (and missing) with current surveying schemes? and 3) What would be an optimal surveying strategy?

\section{Results}

Under the first order assumption that beach evolution is predominantly subject to incident wave conditions ${ }^{5,19-21}$, we can use existing wave-data databases to determine beach evolution time-scales and its associated uncertainty ${ }^{16}$ (see Methods for details). The uncertainty of measurable beach evolution time-scales increases rapidly as the time in between surveys increases (Figure S1). A stabilised and distinctive beach evolution time-scale classification is found around a constant global value of $80 \%$ uncertainty. Considering this threshold, a potential global beach change time-scale map is obtained as presented in Figure 1 with a global mean and median time-scale of respectively 48 days and 2 weeks. Local details can be found in the supplementary material: Figure S2.

The global representation in Figure 1a evidently shows clustering patterns. At mid to high latitudes -45 to $60^{\circ}-$ time-scales linked to Westerly storm tracks are found. In the Southern Ocean continuous Westerly storm tracks ${ }^{22}$ result in short - weeklytime-scales only e.g. at the coasts of Patagonia, South Africa, Southern-Australia and New Zealand. While in the North
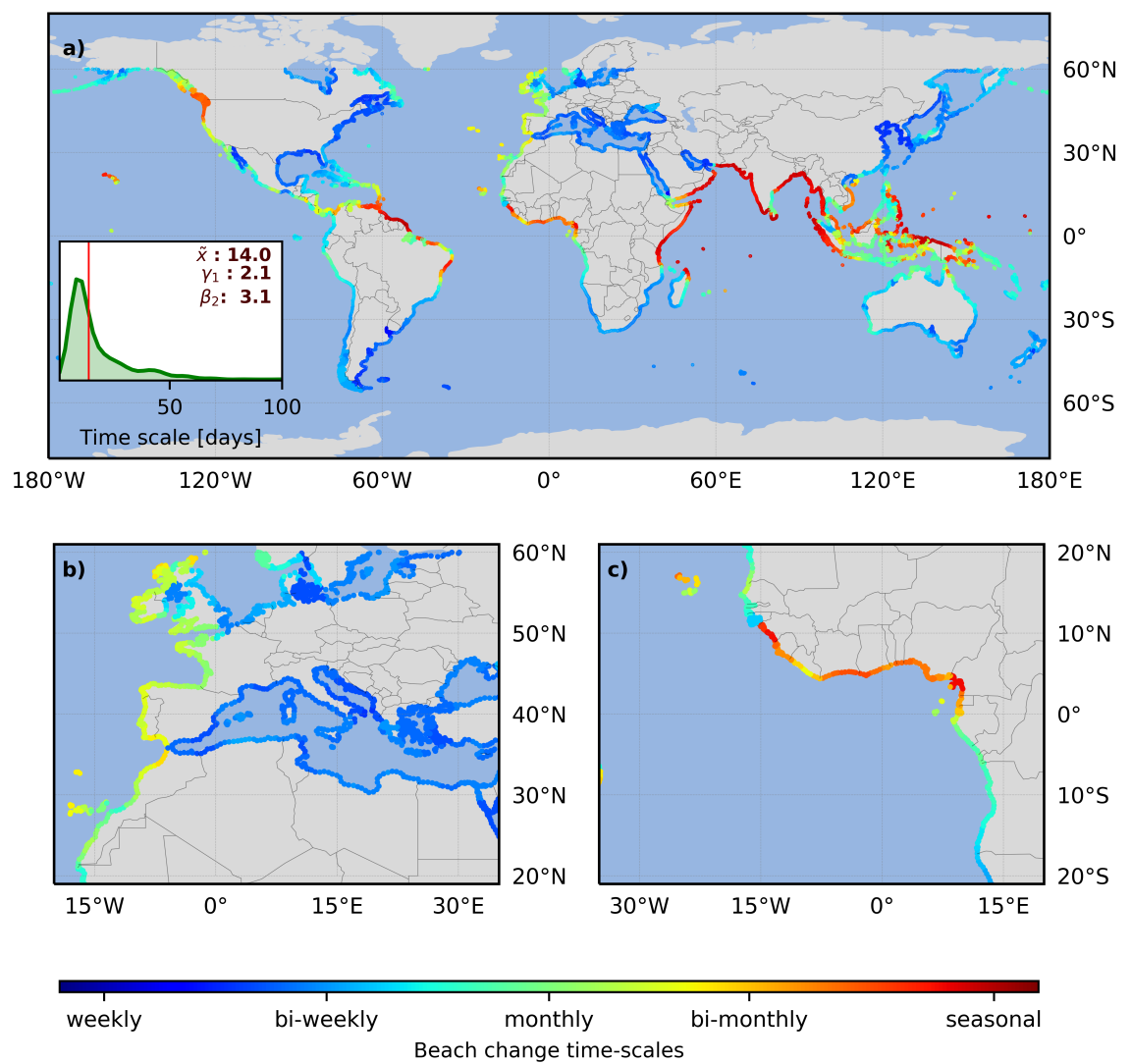

Figure 1. Global beach evolution time-scales and two zooms on b) zoomed part of Europe and Northern Africa and c) a part of Western Africa. The logarithmic colormap covers beach evolution time-scales from a few days until seasonal. Longer beach evolution time-scales seem never to dominate. The insert in a) represents a distribution of the global time-scales. The red vertical line in the insert indicates the median global value for beach evolution time-scales. 
Atlantic and North Pacific oceans Westerly storm-tracks ${ }^{23,24}$ result in storm-season dominated west coasts (Western-Europe and West-coast of Northern America) and short (about bi-weekly) beach evolution time-scales at the east-coasts of North America, Russia and Japan. The inter-tropical band has strong seasonality and dominate longer time-scales in the order of bi-monthly to seasonal are found. This can be linked to the dominance of monsoon seasons and related winds and waves as well as remote swell arriving from higher latitudes ${ }^{22,25}$. Closed or protected seas/gulfs such as the Mediterranean sea, the Black sea, the Persian Gulf, Sea of Japan or the Gulf of Mexico experience predominantly exposure to locally generated wind sea waves, hence the short beach evolution time-scales.

In Figure 1b,c we illustrate the clustering by zooming in on mid-latitude storm-dominated European coasts (b) and equatorial to tropical West-Africa (c). Figure 1b shows a coherent beach change time-scale behaviour around Europe' shores. At the Atlantic coast, exposed to ocean swells, a seasonal signal is found in the incident wave energy flux. This seasonal fluctuation in the wave energy flux holds that uncertainty remains low over significantly longer time-scales, hence the monthly to bi-monthly morphological time-scales. In the Mediterranean sea, which is sheltered from these ocean swells, locally generated wind-sea waves dominate. Short crested low period waves (which are punctual and show little long-term fluctuations) are typically found in these regions. Accordingly, the measurable certainty deteriorates relatively rapidly resulting in dominant short beach change time-scales.

For West-Africa (Figure 1c), an apparent North to South shorter-longer-shorter shift in time-scales can be found -20 to $10^{\circ}$ $\mathrm{N}, 10^{\circ} \mathrm{N}$ to $0^{\circ}$ and $0^{\circ}$ to $20^{\circ} \mathrm{S}-$. Between $20^{\circ}$ and $10^{\circ} \mathrm{N}$ short beach evolution time-scales can be assigned to the combination of Northerly and Southerly swell ${ }^{26}$. The combination of the two swell results in limited seasonality leading to a rapid decline in observable variability as survey-interval decreases ${ }^{27}$. Whereas in the Gulf of Guinea, the Northerly swell does not penetrate to the coast leaving this part open to the Southerly longer fluctuations in wave energy flux ${ }^{28}$. From the equator South (latitudes 0 20S), trade winds play a major role. As a consequence, shorter beach evolution time-scales are found.

Above results show that wave-forcing has a certain temporal scale. Also, they have spatial scales; which are mostly overlooked in coastal studies. For example, a storm hitting Western Europe will drives changes at a regional level (i.e. the synoptic scale of the storm and subsequent waves), with different local beach changes, but regionally linked ${ }^{6}$. Climate modes drive change in coastal waves at an even greater scale. It is key to determine these scales to design appropriate surveying strategies and sampling distances along the coast: kilometres, tens of kilometres, hundreds of kilometres? For instance, there is little added value -perhaps even a waste of energy and resources- to survey 2 closely situated beaches if their beach change is

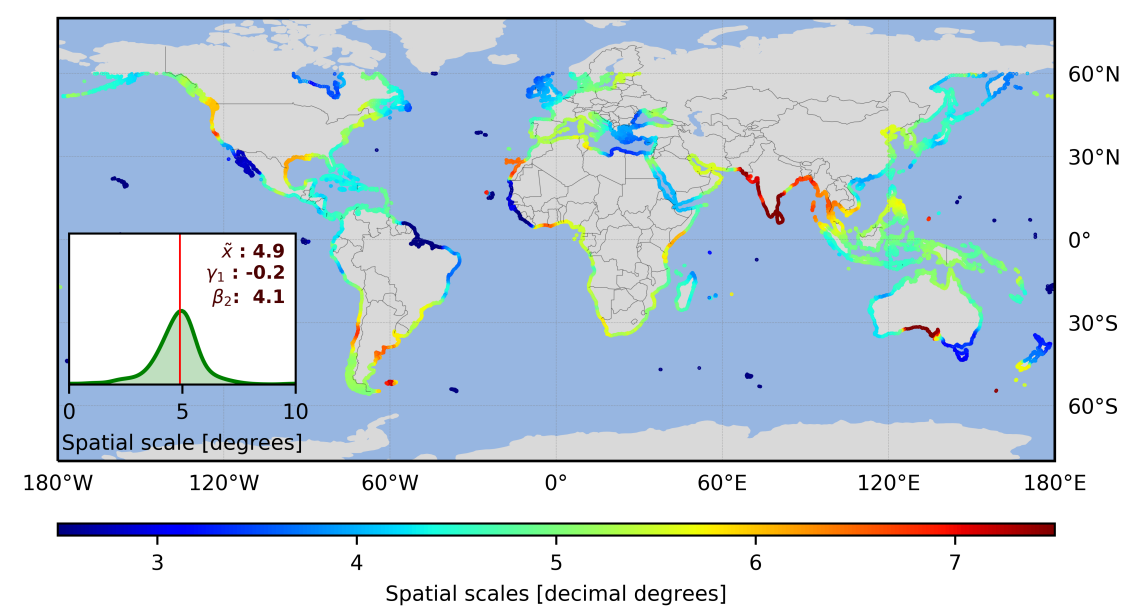

Figure 2. Global distribution of spatial spheres of influence, the maximum extend of correlated wave time-series (see Method section). Correlated distance is plotted per location along the world' coastline including an insert showing the global distribution and median (vertical red line). It is evident from this figure that for the dominant time-scales, correlated wave signals are found within a radius of around 4.9 degrees $(550 \mathrm{~km}$ at the equator). 
well correlated. If the dominant timescale is picked (Figure 2, this dominant spatial scale is 4.8 degrees -representing 540 $\mathrm{km}$ at the equator-, and shows a great contrast worldwide. Largest values are encountered in the Arabian Sea and the Bay of Bengal around India and smallest in on the boundary between the Northern and Southern Atlantic (North Brasil and Part of West-Africa). Small basins and closed sea such as the Mediterranean region can be considered as single clusters as well as islands.

\section{Discussion}

\section{Uncertainty of conventional surveying schemes}

Several long-term ongoing surveying schemes typically carry out beach surveys on near-continuous (video camera), monthly, bi-monthly or yearly basis $7,18,26,29-32$. The surveying frequency seems to depend on the purpose of the survey: science applications often show a higher surveying frequency then policy-based (district or national) surveys. A question raised how much of the natural beach change can be captured for each of these surveying frequencies? Figure 3 shows the global uncertainty distribution of monthly surveys.

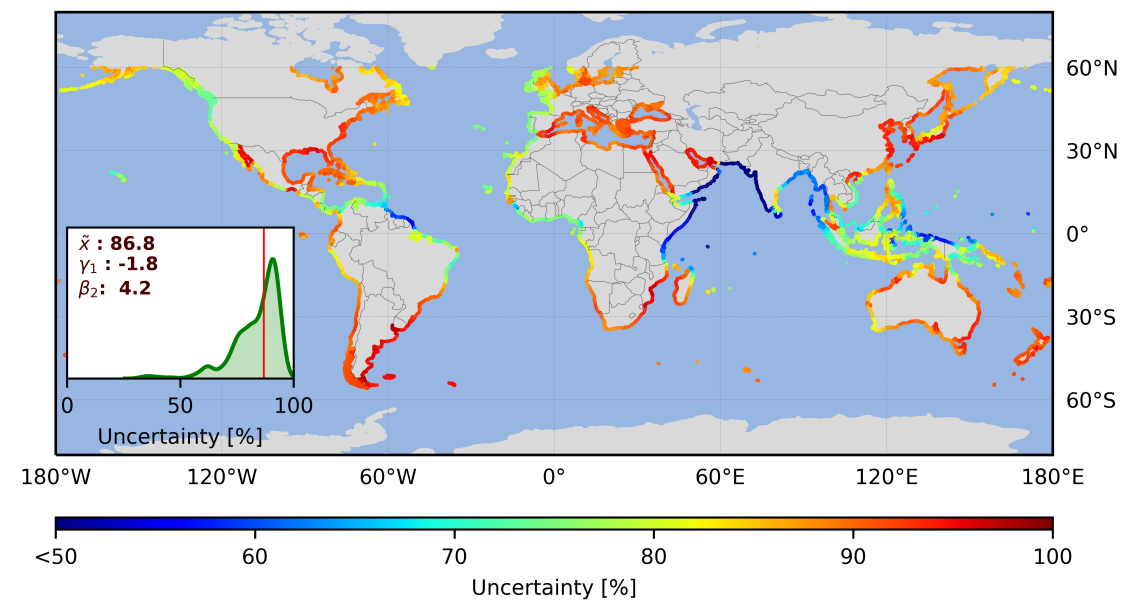

Figure 3. Global statistical measurement-uncertainty distribution associated to beach surveys with a monthly interval. It is evident that monthly beach measurements have high associated uncertainty. The insert highlights this uncertainty: $98.4 \%$ of monthly beach measurements has more than $50 \%$ uncertainty. The vertical red-line represents the median uncertainty of $86.8 \%$.

Considering Figure 3 it is evident that we find high uncertainty linked to monthly surveying campaigns. A vast majority (98.4\%) of the globally distributed analysis-points have an uncertainty of 50\% or higher with a median of $86.9 \%$. Regional patterns in uncertainty can be found in Figure 3 linked beach change time-scales (Figure 1). Typically larger uncertainties are found at regions with shorter -unresolved- beach change time-scales, and vice versa. Similar patterns can be found in case of weekly and bi-monthly surveying schemes, presented in the supplementary figures section in Figure S3. Even the highly expensive weekly surveying schemes often exceed the 50\% uncertainty threshold. Evidently in Figure S3, as the surveying time-interval increases, the median uncertainty increases. In the case of yearly surveys, this means that over the 24-years signal we find near $100 \%$ global uncertainty (see Method section for more details). Hence, such high uncertainty holds that with yearly survey schemes, the inter-annual beach evolution time-scales cannot be resolved -the observed beach evolution is not significant-; e.g. a yearly measurement might be taken just before or after an erosional event such as storms.

\section{Optimal surveying strategies}

Monthly field-measurements capture only a fraction of the total beach-change with high uncertainty, and short time-scale beach evolution is largely missed. Between monthly and bi-monthly surveys the uncertainty does not further increases at most locations around the world. In other words, it does not matter if you survey bi-monthly or monthly; your observation carries a 
similar measurement-uncertainty. Hence, it is more efficient/optimal to have lower surveying frequency while maintaining a similar certainty while permitting other beaches to be surveyed. Following this philosophy, an optimum surveying frequency can be found at which we maintain the certainty of the measurement with the lowest surveying frequency, as shown in Figure 4.

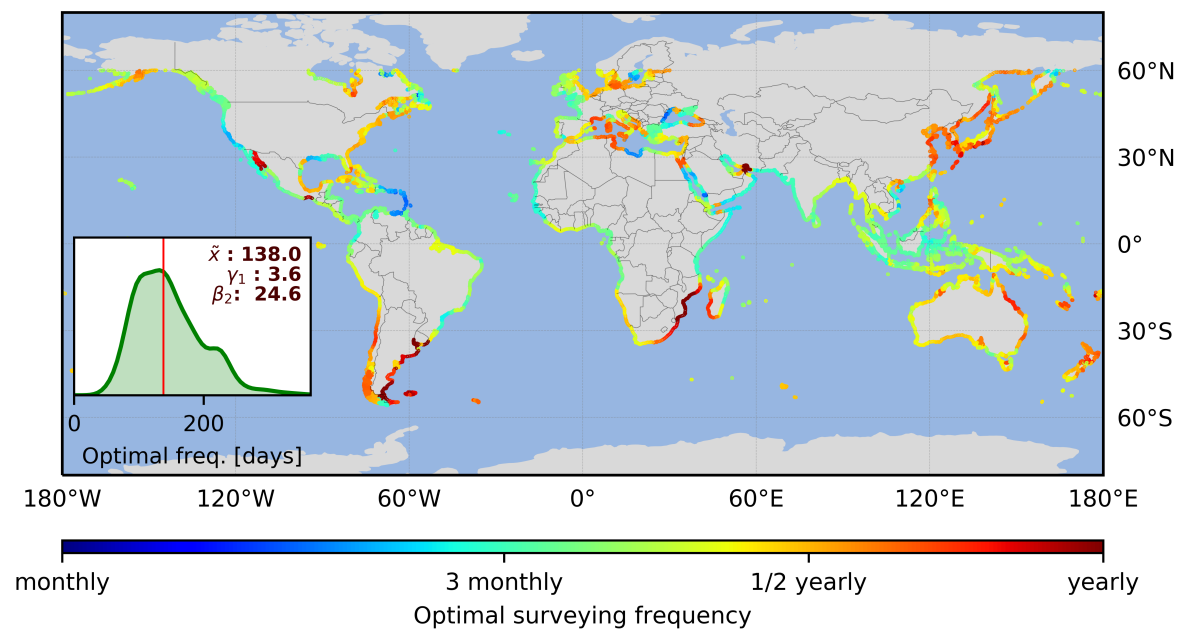

Figure 4. Global distribution of optimal surveying frequency depending on the limited gain/loss of uncertainty. The insert shows the global distribution and the red vertical line represents the median value (138 days).

After an initial rapid increase, the uncertainty remains near-constant before reaching $100 \%$ uncertainty. The optimal surveying frequency lies at the point that the uncertainty starts to increase again to $100 \%$, indicated by the dashed green line in Figure S1. Optimal surveying frequencies are calculated through a 3-phase process, 1) the inflection point at which the uncertainty stagnates, 2) the corresponding uncertainty (these two steps can be found in Figure S5) and 3) optimal surveying frequency is then the frequency at which the uncertainty starts to increase again, exceeding a $5 \%$ uncertainty increase.

Global optimal surveying frequencies, as in Figure 4, range between monthly and yearly, with a median of 138 and a mean of 151 days (for convenience just under half a year). At places where short beach-change time-scales dominate, a low optimum surveying frequency (large time-interval) can be found. This can be explained by the fact that much of the certainty in the signal is lost at short time-intervals before the inflection point time-scales found in Figure S5a. Following the earlier proposed philosophy: we are unable to resolve the signal anyway, so, little purpose to measure those beaches often (i.e. low gain over effort ratio). The opposite is true for beaches with longer time-scales; the more seasonal beach change time-scale dominated beaches.

\section{A more complex beach response}

This analysis on a global scale compels assumptions such as a direct link between beach change response and offshore waves while smaller-scale -local- coastal dynamics are generally more complex. The link between met-ocean forcing and beach response is insufficiently understood and deserves further research effort, in particular at large scales ${ }^{33}$. Sea level, including astronomical and atmospherical (surge) tide conditions play a role ${ }^{34,35}$. For example, storm impact depends on when a storm hits the coast, during low -less impact- or high-tide-more impact- ${ }^{6,7}$. Tides also have a more general damping effect in terms of the residence time of wave action. For example, in the Mediterranean sea (micro-tidal) the wave action is concentrated while the large tidal ranges of macro tidal environments -such as England' North-Cornish coast- experience greater spreading of the wave action ${ }^{36,37}$. Earlier studies also pointed out a certain lag, a beach response time, between wave conditions and beach change. Hence, making beach response less prone to direct incident wave energy flux. Unfortunately, a single, constant, global beach response time value does not seem to exist: site-specific beach response time values are found, ranging from days, weeks to years (effectively the mean) $)^{5,8,18}$.

Our results of uncertainty are therefor perhaps too pessimistic, and thus we expect to gain certainty taking into account 

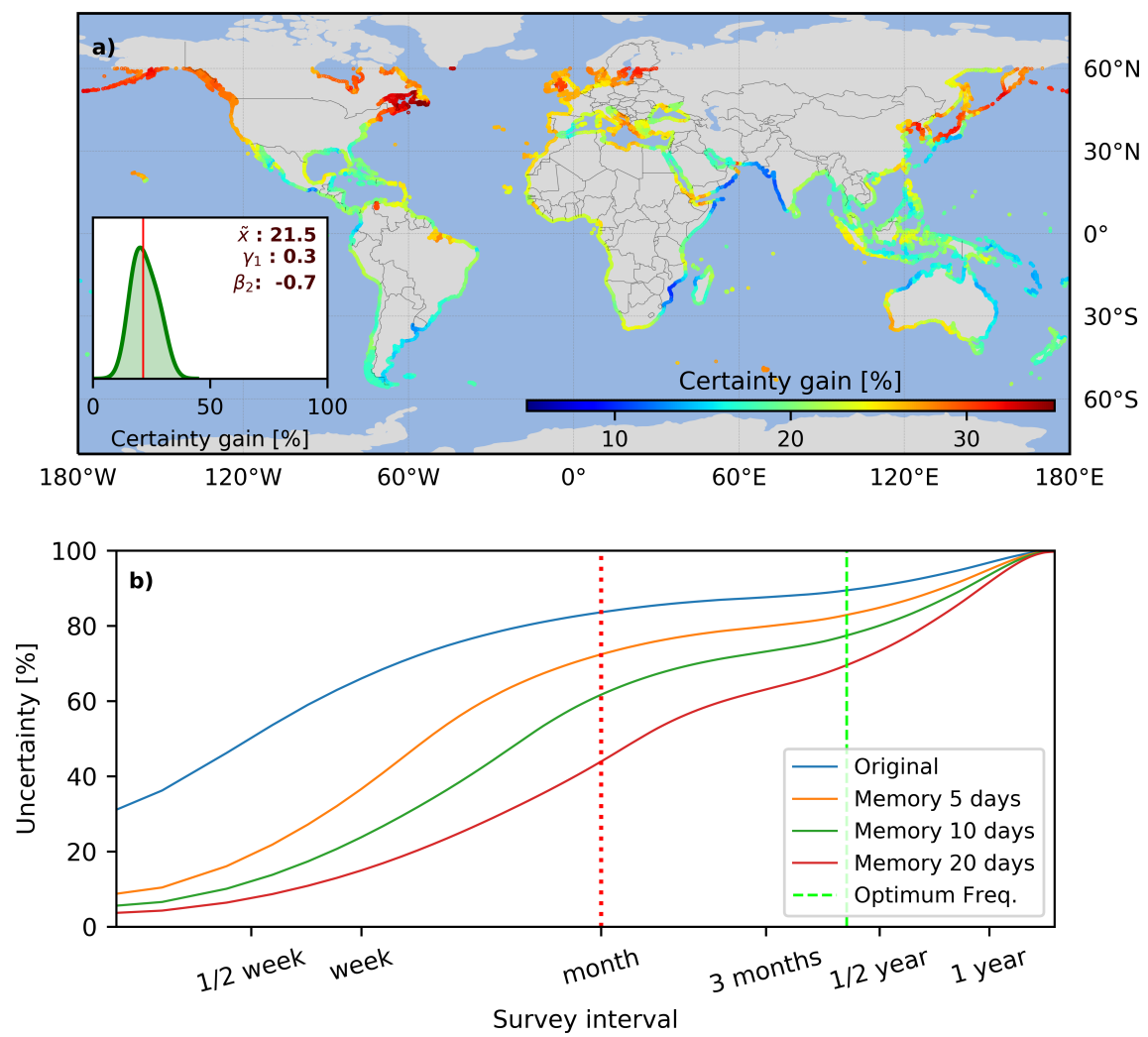

Figure 5. The effect of beach memory on statistical measurement-uncertainty. a) Global certainty gain for a monthly surveying frequency considering beach memory of 10 days. b) Worldwide average uncertainty for the original analysis and beach memory of 5, 10 and 20 days. The red dotted vertical line indicates the monthly surveying time-interval while the vertical green dashed line shows the average optimum surveying frequency as found above.

memory decay (Figure 5). Considering a beach memory of 10 days (earlier observed by ${ }^{36,38,39}$ ) -as in Figure 5a)-, we indeed find that we generally gain certainty by including a memory decay factor. In case of monthly surveys, the average global certainty gain is around $22.2 \%$ and the distribution plot in Figure 5a reveals that the gain is quite narrowly distributed (standard deviation $=5 \%$ ). Interestingly, the largest certainty gains are found at storm wave-dominated mid-latitudes ${ }^{40}$ in the Northern Hemisphere $\left(30-60^{\circ} \mathrm{N}\right)$. In case of longer -seasonal- beach evolution time-scales (as found in the Arabian Sea- Figure 1a), the gain is limited. Noteworthy, the optimal surveying frequency seems unaffected for these beach memory values. As mentioned briefly, a constant beach memory factor is perhaps inconsistent with reality.

The lack of in-situ measurements and/or remotely sensed shoreline data to define global distributions of beach response times highlights the importance to intensify observation ${ }^{33}$, for example, the use of spaceborne coastal observation ${ }^{14}$, which is particularly feasible for mid to high latitudes ${ }^{41}$. Recently, a combined availability of optical satellite data and computational power on cloud platforms ${ }^{42}$ enabled a global assessment of coastline change ${ }^{43}$. With back-dateable, easy-access shorelinetracking ${ }^{44}$, emerging spatial topography ${ }^{45}$, increasingly more accurate bathymetry estimation techniques e.g. ${ }^{42,46-48}$, on-demand very high-resolution satellites every day everywhere in the world (e.g. Pleiades or Worldview), a Sentinel-2 revisit time at the coast of at maximum 5 days -but often less ${ }^{41}$ - and in combination with Landsat and dozens of optical cube-satellites, the future is bright. 


\section{Methods}

We use the ERAInterm global re-analysis ${ }^{49}$ to determine wave changes. From the ERAInterm database, 6-hourly wave heights and energy period are extracted along the world' coastlines (equally spaced over 14140 points) covering a 24-year period from January 1993 to January 2017. From these parameters the incident energy flux is computed as shown in Equation 1 so that for each of the 14140 points we thus have a 24-year time-series of incident wave energy flux $(E f)$.

$$
E f=\frac{\rho g^{2}}{64 \pi} H_{s}^{2} T_{e}
$$

In which $\rho$ refers to the water density (a global value of $1025 \mathrm{~kg} / \mathrm{m}^{3}$ is used), $g$ represents gravitational acceleration (for which a global value of 9.8 is used), $H_{s}$ is the significant wave height and $T_{e}$ is the corresponding wave energy period. The observational time-interval $\left(\Delta t_{o b s}\right)$ determines to a great extent what time-scales one can resolve for. Here we analyse the effect of increasingly sparser sampling in terms of uncertainty. If we capture the signal at our maximum temporal resolution (6 hours), full potential beach evolution is observed resulting in $0 \%$ uncertainty. Subsequently, the sampling frequency is decreased and the captured uncertainty increases. Instead of taking an absolute $\Delta t$ diminishing the number of data points, we decrease the sampling frequency by enlarging the running average window, $\Delta t$ in Equation 2.

$$
\text { Uncertainty }=\frac{\sigma\left(E f-\frac{1}{\Delta t_{o b s}} \sum_{i=-\Delta t_{\text {obs }} / 2}^{\Delta t_{\text {obs }} / 2} E f_{i}\right)}{\sigma(E f)}
$$

in which $\sigma$ is the standard deviation, $\Delta t_{o b s}$ time interval between observations and $E f$ is the incident energy flux. Depending on the wave climate and its temporal variations, the uncertainty increases either rapidly or remains low for longer time intervals. For example, wave environments with relatively little seasonality gain uncertainty rapidly while for wave climates with a greater seasonality the uncertainty remains low for longer time-scales. What we will see below is that the uncertainty often increases significantly between data' sampling rate (every 6 hours) to week time-interval: on average 60-80\%, as illustrated in Figure S1. The spatial correlation was computed at different timescales, using pass-band filter over wave time-series. A threshold of half peak was applied to determine the representative distance of correlation.

\section{Acknowledgements}

Erwin Bergsma is funded through a CNES-postdoctoral fellowship (CNES - French National Space Agency). All global maps has been created with Metoffice' cartopy package ${ }^{50}$.

\section{Author contributions statement}

EB idea, analysis, experimental setup, figures, early drafting, final manuscript. RA idea, experimental setup, final manuscript. TG, final manuscript. EK data collection and final manuscript.

\section{References}

1. Vitousek, S. et al. Doubling of coastal flooding frequency within decades due to sea-level rise. Sci. Reports 7, 1399, DOI: 10.1038/s41598-017-01362-7 (2017).

2. Melet, A., Meyssignac, B., Almar, R. \& Le Cozannet, G. Under-estimated wave contribution to coastal sea-level rise. Nat. Clim. Chang. 8, 234-239, DOI: 10.1038/s41558-018-0088-y (2018). 
3. Vousdoukas, M. I. et al. Sandy coastlines under threat of erosion. Nat. Clim. Chang. 10, 260-263, DOI: https://doi.org/10. 1038/s41558-020-0697-0 (2020).

4. Giardino, A. et al. A quantitative assessment of human interventions and climate change on the west african sediment budget. Ocean. \& Coast. Manag. 156, 249 - 265, DOI: https://doi.org/10.1016/j.ocecoaman.2017.11.008 (2018). SI: MSforCEP.

5. Davidson, M., Splinter, K. \& Turner, I. A simple equilibrium model for predicting shoreline change. Coast. Eng. 73, 191 202, DOI: https://doi.org/10.1016/j.coastaleng.2012.11.002 (2013).

6. Masselink, G. et al. The extreme 2013/2014 winter storms: hydrodynamic forcing and coastal response along the southwest coast of england. Earth Surf. Process. Landforms 41, 378-391, DOI: 10.1002/esp.3836 (2016). https: //onlinelibrary.wiley.com/doi/pdf/10.1002/esp.3836.

7. Bergsma, E. W. J., Conley, D. C., Davidson, M. A., O`Hare, T. J. \& Almar, R. Storm event to seasonal evolution of nearshore bathymetry derived from shore-based video imagery. Remote. Sens. 11, DOI: 10.3390/rs11050519 (2019).

8. Almar, R. et al. Shoreline response to a sequence of typhoon and monsoon events. Water 9, DOI: 10.3390/w9060364 (2017).

9. Rogers, J. et al. Beach Management Manual (Construction Industry Research and Information Association, London, United Kingdom, 2010).

10. Turner, R. K., Subak, S. \& Adger, W. N. Pressures, trends, and impacts in coastal zones: Interactions between socioeconomic and natural systems. Environ. Manag. 20, 159-173, DOI: 10.1007/BF01204001 (1996).

11. Becker, M., Karpytchev, M. \& Lennartz-Sassinek, S. Long-term sea level trends: Natural or anthropogenic? Geophys. Res. Lett. 41, 5571-5580, DOI: 10.1002/2014GL061027 (2014).

12. Nicholls, R. J. \& Tol, R. S. Impacts and responses to sea-level rise: a global analysis of the sres scenarios over the twentyfirst century. Philos. Transactions Royal Soc. A: Math. Phys. Eng. Sci. 364, 1073-1095, DOI: 10.1098/rsta.2006.1754 (2006). https://royalsocietypublishing.org/doi/pdf/10.1098/rsta.2006.1754.

13. Vousdoukas, M. I. et al. Global probabilistic projections of extreme sea levels show intensification of coastal flood hazard. Nat. Commun. 9, 2360, DOI: 10.1038/s41467-018-04692-w (2018).

14. Benveniste, J. et al. Requirements for a coastal hazards observing system. Front. Mar. Sci. 6, 348, DOI: 10.3389/fmars. 2019.00348 (2019).

15. Schepper, R. et al. Modelling cross-shore shoreline change on multiple timescales. J. Geophys. Res. Earth Surf. in review. (2020).

16. Plant, N. G., Holland, K. \& Puleo, J. A. Analysis of the scale of errors in nearshore bathymetric data. Mar. Geol. 191, 71 86, DOI: https://doi.org/10.1016/S0025-3227(02)00497-8 (2002).

17. Harley, M. D., Turner, I. L., Short, A. D. \& Ranasinghe, R. Assessment and integration of conventional, rtk-gps and image-derived beach survey methods for daily to decadal coastal monitoring. Coast. Eng. 58, 194 - 205, DOI: https://doi.org/10.1016/j.coastaleng.2010.09.006 (2011).

18. Splinter, K. D. et al. A generalized equilibrium model for predicting daily to interannual shoreline response. J. Geophys. Res. Earth Surf. 119, 1936-1958, DOI: 10.1002/2014JF003106 (2014). https://agupubs.onlinelibrary.wiley.com/doi/pdf/10. 1002/2014JF003106.

19. Yates, M. L., Guza, R. T., O'Reilly, W. C., Hansen, J. E. \& Barnard, P. L. Equilibrium shoreline response of a high wave energy beach. J. Geophys. Res. Ocean. 116, DOI: 10.1029/2010JC006681 (2011). https://agupubs.onlinelibrary.wiley. com/doi/pdf/10.1029/2010JC006681. 
20. Barnard, P. L. et al. Extreme oceanographic forcing and coastal response due to the 2015-2016 el niño. Nat. Commun. 8, 14365, DOI: 10.1038/ncomms14365 (2017).

21. Huppert, K. L., Perron, J. T. \& Ashton, A. D. The influence of wave power on bedrock sea-cliff erosion in the Hawaiian Islands. Geology DOI: 10.1130/G47113.1 (2020). https://pubs.geoscienceworld.org/geology/article-pdf/doi/10.1130/ G47113.1/4961168/g47113.pdf.

22. O’Kane, T. J., Matear, R. J., Chamberlain, M. A., Oliver, E. C. J. \& Holbrook, N. J. Storm tracks in the southern hemisphere subtropical oceans. J. Geophys. Res. Ocean. 119, 6078-6100, DOI: 10.1002/2014JC009990 (2014).

23. Hoskins, B. J. \& Hodges, K. I. The annual cycle of northern hemisphere storm tracks. part i: Seasons. J. Clim. 32, 1743-1760, DOI: 10.1175/JCLI-D-17-0870.1 (2019).

24. Hoskins, B. J. \& Hodges, K. I. The annual cycle of northern hemisphere storm tracks. part ii: Regional detail. J. Clim. 32, 1761-1775, DOI: 10.1175/JCLI-D-17-0871.1 (2019).

25. Hoskins, B. J. \& Hodges, K. I. A new perspective on southern hemisphere storm tracks. J. Clim. 18, 4108-4129, DOI: 10.1175/JCLI3570.1 (2005).

26. Abessolo Ondoa, G. et al. Beach response to wave forcing from event to inter-annual time scales at grand popo, benin (gulf of guinea). Water 9, DOI: 10.3390/w9060447 (2017).

27. Almar, R., Kestenare, E. \& Boucharel, J. On the key influence of remote climate variability from tropical cyclones, north and south atlantic mid-latitude storms on the senegalese coast (west africa). Environ. Res. Commun. 1, 071001, DOI: 10.1088/2515-7620/ab2ec6 (2019).

28. Almar, R. et al. Response of the bight of benin (gulf of guinea, west africa) coastline to anthropogenic and natural forcing, part1: Wave climate variability and impacts on the longshore sediment transport. Cont. Shelf Res. 110, 48-59 (2015).

29. Splinter, K. D., Turner, I. L. \& Davidson, M. A. How much data is enough? the importance of morphological sampling interval and duration for calibration of empirical shoreline models. Coast. Eng. 77, 14 - 27, DOI: https://doi.org/10.1016/j. coastaleng.2013.02.009 (2013).

30. Dyer, T., Brodie, K. L. \& Spore, N. Near Real-Time Collection, Processing, and Publication of Beach Morphology and Oceanographic LIDAR Data. In American Geophysical Union, Ocean Sciences Meeting 2016, abstract \#OD24C-2476 (2016).

31. Biausque, M. \& Senechal, N. Seasonal morphological response of an open sandy beach to winter wave conditions: The example of biscarrosse beach, sw france. Geomorphology 332, 157 - 169, DOI: https://doi.org/10.1016/j.geomorph.2019. 02.009 (2019).

32. Brodie, K., Conery, I., Cohn, N., Spore, N. \& Palmsten, M. Spatial variability of coastal foredune evolution, part a: Timescales of months to years. J. Mar. Sci. Eng. 7, DOI: 10.3390/jmse7050124 (2019).

33. Ranasinghe, R. On the need for a new generation of coastal change models for the 21 st century. Sci. Reports 10, 2010, DOI: 10.1038/s41598-020-58376-x (2020).

34. Ondoa, G. A. et al. Beach adaptation to intraseasonal sea level changes. Environ. Res. Commun. DOI: https://doi.org/10. 1088/2515-7620/ab8705 (2020).

35. Almeida, L. P. et al. Lidar observations of the swash zone of a low-tide terraced tropical beach under variable wave conditions: the nha trang (vietnam) coastvar experiment. J. Mar. Sci. Eng. (2020).

36. Karunarathna, H., Pender, D., Ranasinghe, R., Short, A. D. \& Reeve, D. E. The effects of storm clustering on beach profile variability. Mar. Geol. 348, 103 - 112, DOI: https://doi.org/10.1016/j.margeo.2013.12.007 (2014).

37. Almar, R. et al. Two and three-dimensional double-sandbar system behaviour under intense wave forcing and a meso-macro tidal range. Cont. Shelf Res. 30 (7), 781-792 (2010). 


\section{Non-peer reviewed EarthArXiv preprint}

38. Ranasinghe, R. et al. Quantifying nearshore morphological recovery time scales using argus video imaging: palm beach, sydney and duck, north carolina. Coast. Eng. Proc. 1, 24, DOI: 10.9753/icce.v33.sediment.24 (2012).

39. Angnuureng, D. B. et al. Shoreline resilience to individual storms and storm clusters on a meso-macrotidal barred beach. Geomorphology 290, 265 - 276, DOI: https://doi.org/10.1016/j.geomorph.2017.04.007 (2017).

40. Davies, J. Geographical Variation to Coastal Development (Longman (Pearson Education Limited), 1980), 2nd edn.

41. Bergsma, E. W. J. \& Almar, R. Coastal coverage of esa' sentinel 2 mission. Adv. Space Res. DOI: https://doi.org/10.1016/j. asr.2020.03.001 (2020).

42. Traganos, D., Poursanidis, D., Aggarwal, B., Chrysoulakis, N. \& Reinartz, P. Estimating satellite-derived bathymetry (sdb) with the google earth engine and sentinel-2. Remote. Sens. 10, DOI: 10.3390/rs10060859 (2018).

43. Luijendijk, A. et al. The state of the world's beaches. Nature,Scientific Reports 8 article 6641, DOI: 10.1038/ s41598-018-24630-6 (2018).

44. Vos, K., Harley, M. D., Splinter, K. D., Simmons, J. A. \& Turner, I. L. Sub-annual to multi-decadal shoreline variability from publicly available satellite imagery. Coast. Eng. 150, 160 - 174, DOI: https://doi.org/10.1016/j.coastaleng.2019.04.004 (2019).

45. Almeida, L. P. et al. Deriving high spatial-resolution coastal topography from sub-meter satellite stereo imagery. Remote. Sens. 11, DOI: 10.3390/rs11050590 (2019).

46. Caballero, I. \& Stumpf, R. P. Retrieval of nearshore bathymetry from sentinel-2a and $2 \mathrm{~b}$ satellites in south florida coastal waters. Estuarine, Coast. Shelf Sci. 226, 106277, DOI: https://doi.org/10.1016/j.ecss.2019.106277 (2019).

47. Almar, R., Bergsma, E. W. J., Maisongrande, P. \& de Almeida, L. P. M. Wave-derived coastal bathymetry from satellite video imagery: A showcase with pleiades persistent mode. Remote. Sens. Environ. 231, 111263, DOI: https: //doi.org/10.1016/j.rse.2019.111263 (2019).

48. Bergsma, E. W. J., Almar, R. \& Maisongrande, P. Radon-augmented sentinel-2 satellite imagery to derive wave-patterns and regional bathymetry. Remote. Sens. 11, DOI: 10.3390/rs11161918 (2019).

49. Dee, D. P. et al. The era-interim reanalysis: configuration and performance of the data assimilation system. Q. J. Royal Meteorol. Soc. 137, 553-597, DOI: 10.1002/qj.828 (2011). https://rmets.onlinelibrary.wiley.com/doi/pdf/10.1002/qj.828.

50. Met Office. Cartopy: a cartographic python library with a matplotlib interface. Exeter, Devon (2010 - 2019).

51. Wright, L. \& Short, A. D. Morphodynamic variability of surf zones and beaches; a synthesis. Mar. Geol. 56, pp. 93-118 (1984). 


\section{Supplementary material}

\section{Beach response time -memory decay- formulation}

The principle behind the beach response time -also known as beach memory-is that beaches require time to shift from and to equilibrium corresponding to incident wave conditions. Following beach memory decay formulation of ${ }^{51}$, a beach memory filtered wave energy flux signal can be described following equation 3 .

$$
E f_{M}(t)=\frac{\sum_{j=0}^{\frac{D}{\Delta t}} E f_{j} 10^{-j \Delta t / \phi}}{\sum_{j=0}^{\frac{D}{\Delta t}} 10^{-j \Delta t / \phi}}
$$

In which $\phi$ represents the number of days, incident wave energy flux is denoted as $E f$ and $\Delta t$ is the time-interval of the input data - in terms of the number of samples a day.

\section{Supporting figures}

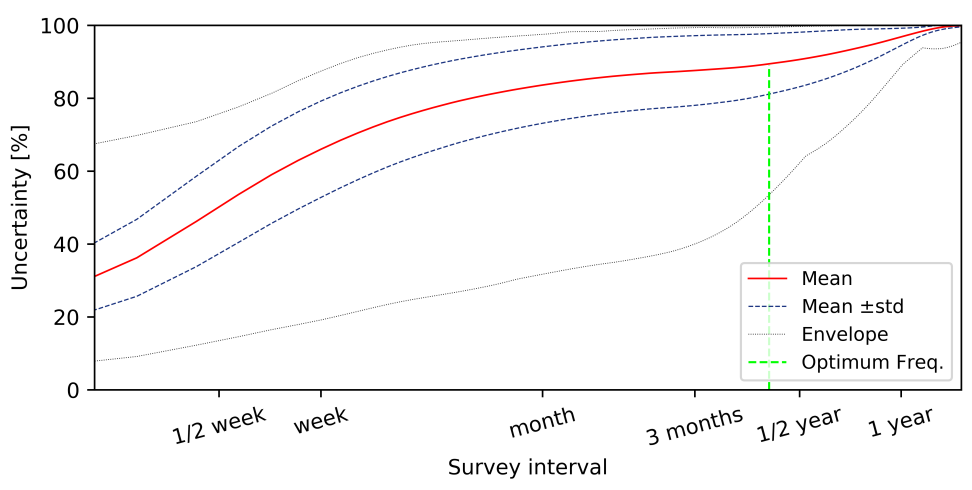

Figure S1. Worldwide average uncertainty distribution per survey interval including the standard deviation (dashed blue lines) and envelope (dotted light grey lines). The green dashed line represents the optimal surveying frequency. 

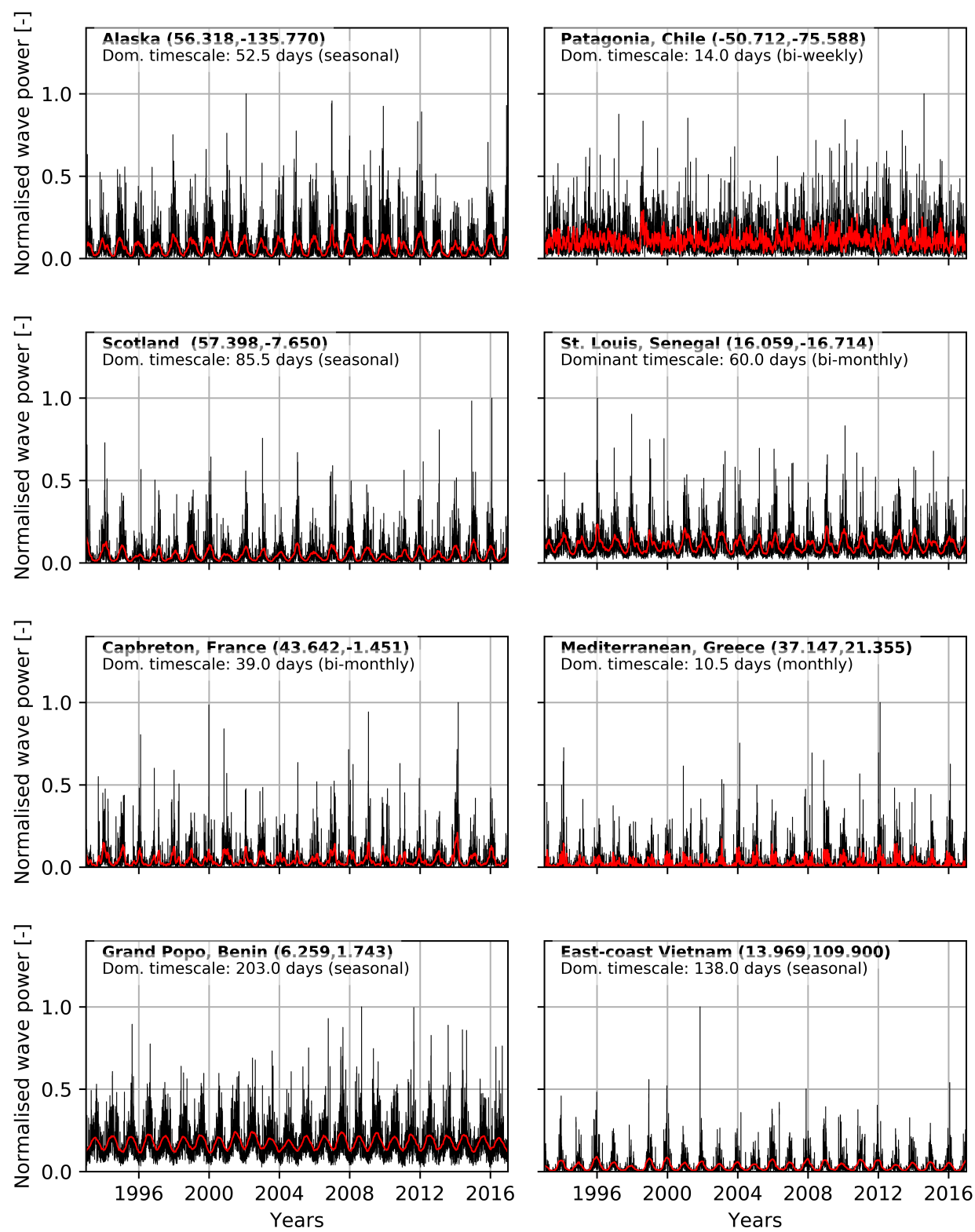

Figure S2. Example time-series spread around the world to highlight the dominant beach evolution time-scales. For example, Patagonia (top-right), continuous storms from the southern ocean makes the dominant beach evolution time-scale short. While Benin (bottom-left) is predominantly exposed to low-frequency fluctuations from distantly generated swells that occasionally propagated through the South Atlantic Ocean. 

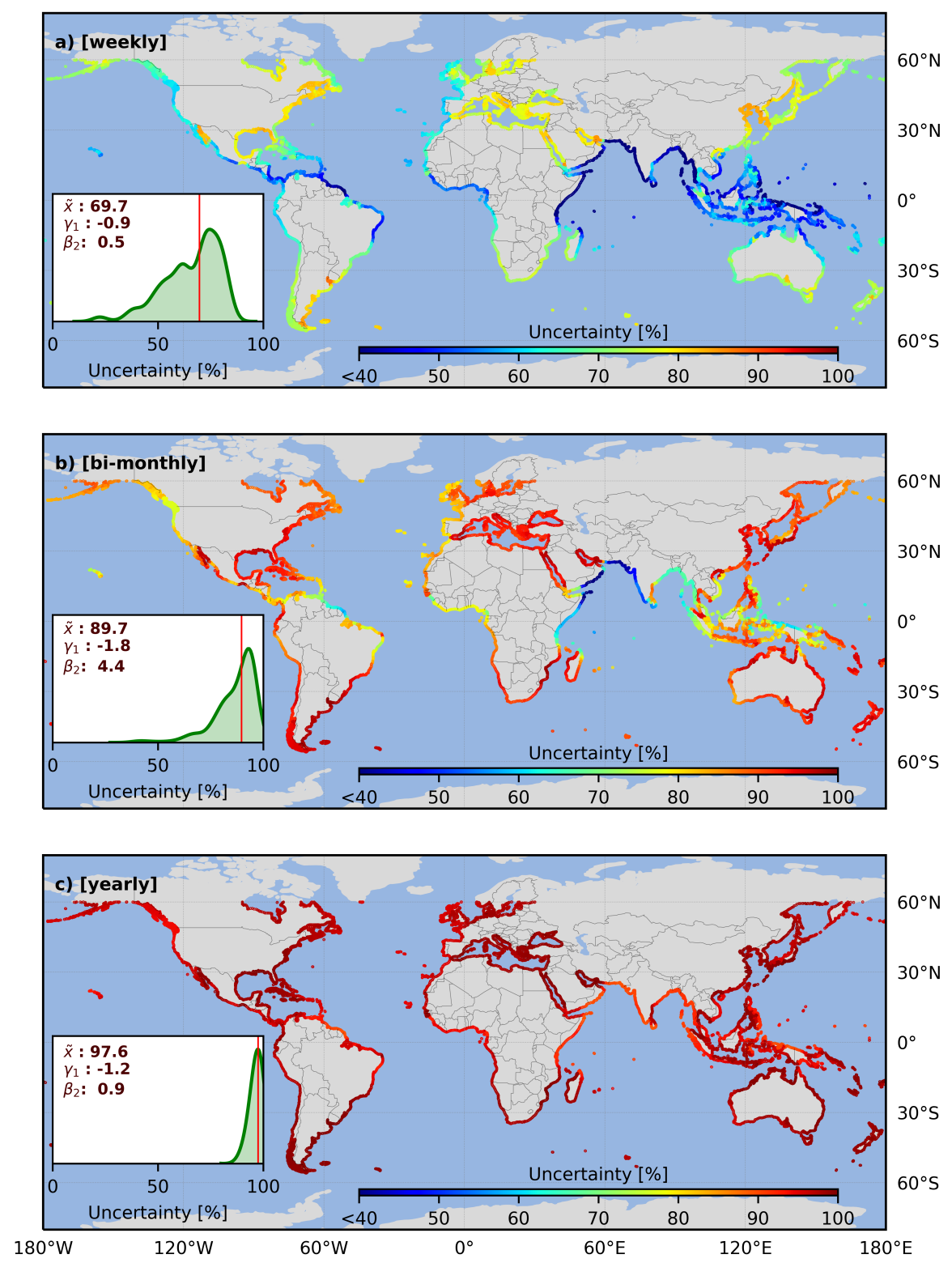

Figure S3. Statistical measurement uncertainty related to a) weekly, b) bi-monthly and c) yearly surveying intervals. As the surveying interval increases, the uncertainty of the measurement increases. For month surveys, measurement uncertainty is lowest for beach in the low-latitudes and relatively high for sheltered seas. Yearly measurements carry great uncertainty that can be explained by, for example, a measurement just before or after a storm and the yearly change/trend can be significantly different. 

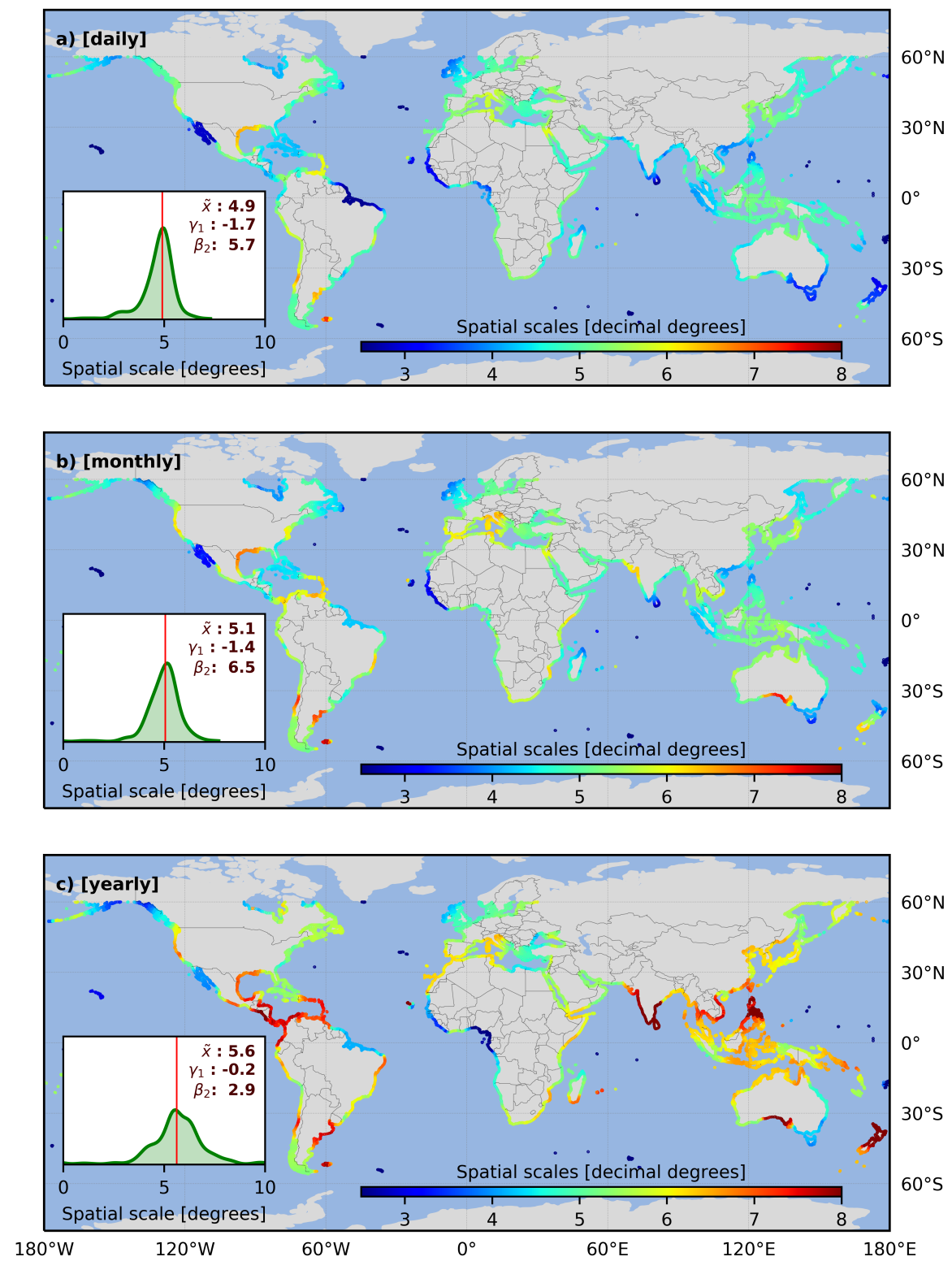

Figure S4. Global spheres of influence related to spatially-correlated wave time-series in case of a) weekly, b) monthly and c) yearly surveying campaigns. This spatial scale increases with the temporal scale considered. From an average of 4.6 degrees (520 km at the equator) for the event scale, the spatial scales up to 5.7 degrees (630 km at the equator) for the annual scale which has broader dynamics. 

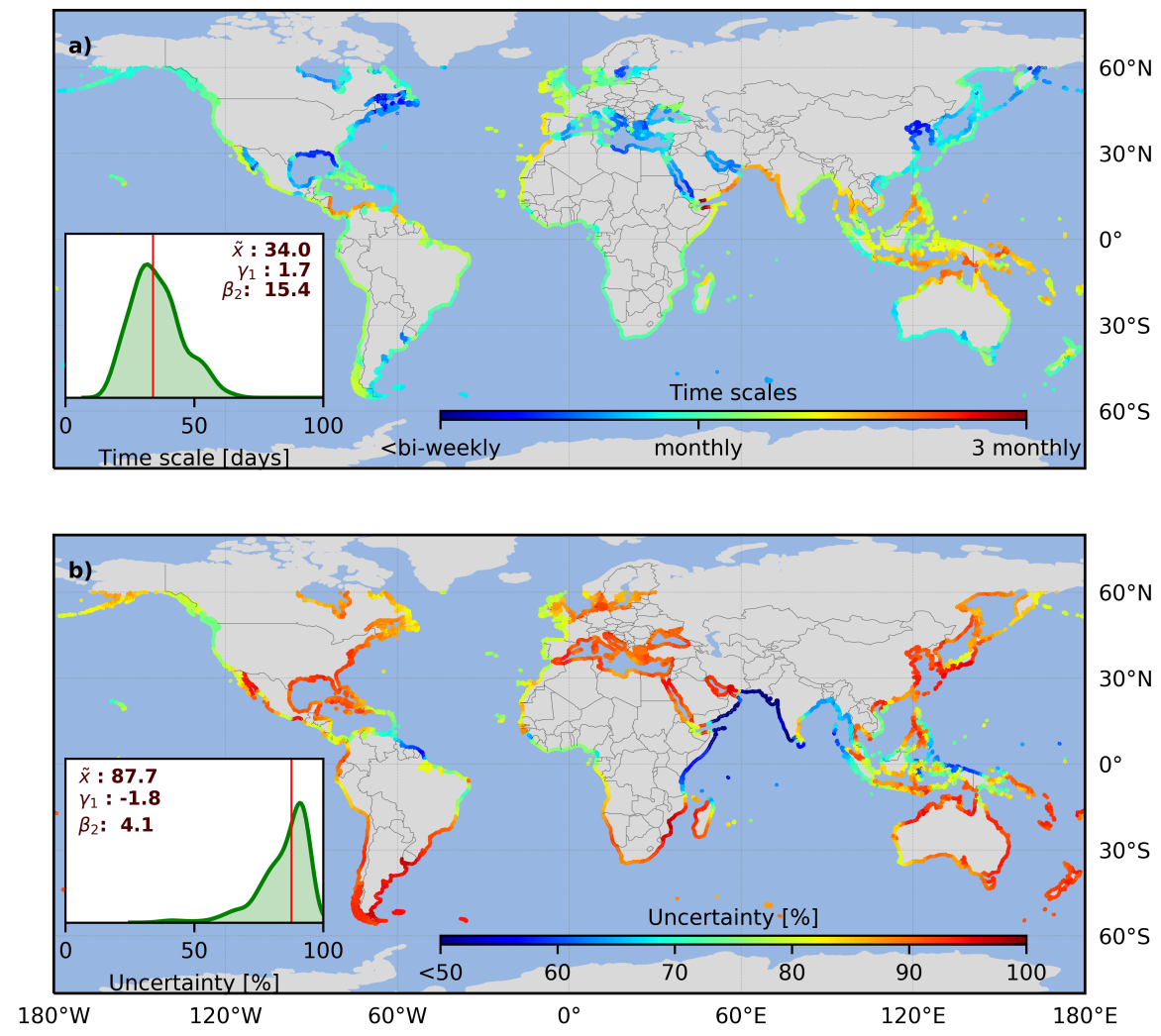

Figure S5. Global representation of a) step 1: a beach change time-scales related to the uncertainty inflection point -stabilizing loss of measurement-certainty and b) a global distribution of the associated uncertainty. 